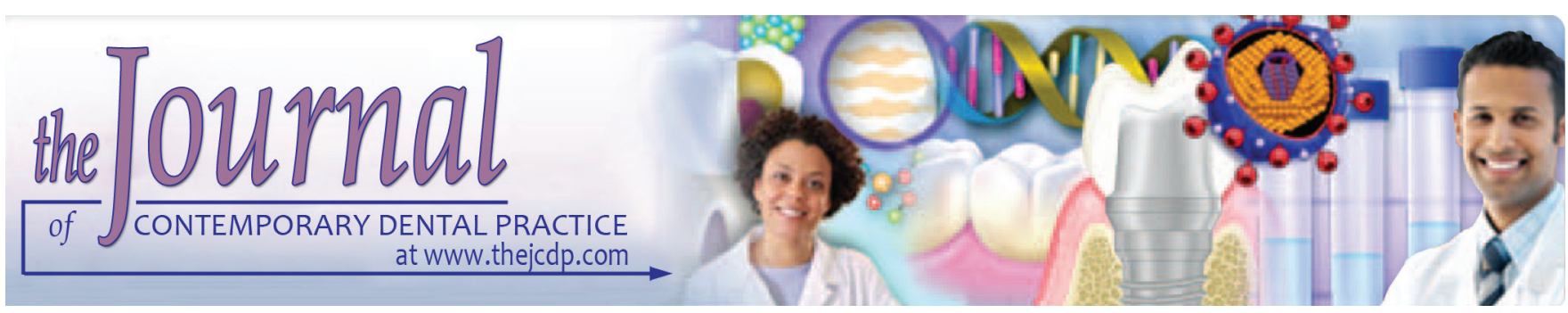

\title{
Correlation between Cervical Vertebrae Volume Parameter and the Skeletal Maturation Status
}

\author{
${ }^{1}$ Ousama A Ayach, ${ }^{2}$ Rania Hadad
}

\begin{abstract}
Aim: Assessing skeletal maturity is a critical factor in orthopedic treatment and orthognathic surgery. Quantitative methods have been suggested to decide the skeletal age. This study aims to assess the correlation between the middle phalanx of the third finger (MP3) method and cervical vertebral volume parameters (CVVP) in skeletal age determination.
\end{abstract}

Materials and methods: This cross-sectional study was conducted on 21 boys and 29 girls between the ages of 8 and 16 years, who were divided into five groups of skeletal maturation: 100 MP3 radiographs and cone beam computed tomography $(\mathrm{CBCT})$ were obtained and analyzed. Middle phalanx of the third finger maturation stages were evaluated according to Perinetti method (stages F-FG-G-H-I). The CVVP was determined on CBCT using Mimics Medical software. Analysis of variance (ANOVA) and Bonferroni tests were utilized to investigate the differences in volumetric parameters between MP3 stages. Spearman correlation coefficient was employed to obtain the correlation between MP3 stages and the CVVP.

Results: The differences in CVVP concentrated between MP3-I stage and the previous stages, with the highest values those for the 4th vertebra. Spearman test revealed a significant highest correlation between MP3 stages and the CVVP in the 4 th vertebra; the lowest was in the $2 n d$, which was higher in the girls group.

Conclusion: Strong level of agreement between the two methods was significant in the 4th vertebra.

Clinical significance: Measurement of volumes of the 4th CVVP could be used as simple quantitative analysis in clinical practice to evaluate the maturity in orthodontic patients.

Keywords: Cervical vertebrae, Growth, Middle phalanx maturation, Quantitative assessment, Skeletal age.

1,2Department of Orthodontics, Faculty of Dental Medicine Damascus University, Damascus, Syria

Corresponding Author: Ousama A Ayach, Department of Orthodontics, Faculty of Dental Medicine, Damascus University Damascus, Syria, Phone: +963988845280, e-mail: Abouayash. ouss@gmail.com
How to cite this article: Ayach OA, Hadad R. Correlation between Cervical Vertebrae Volume Parameter and the Skeletal Maturation Status. J Contemp Dent Pract 2018;19(6):662-668.

Source of support: Nil

Conflict of interest: None

\section{INTRODUCTION}

The rate of growth accelerates and reaches its peak during the adolescence period, and then it declines until adulthood. Timing, duration, rates, and amount of growth vary among individuals during this period. ${ }^{1}$

Orthodontic treatment aims at taking advantage of natural growth spurt of adolescent patient in the case of skeletal discrepancies. ${ }^{2}$

This is especially evident when treatment considerations are strongly based on the facial growth, such as the use of extraoral traction, functional appliances, selection of orthodontic retention, and orthognathic surgery. ${ }^{3}$

A considerable number of growth indicators have been introduced by studies including chronological age, dental age, sexual maturation, and body height. ${ }^{4-8}$

Chronological age could not be used as a reliable indicator to determine the skeletal maturity status.

Prediction of sexual maturity requires a physical examination; hence, the use of sexual maturity as maturation marker is limited in the orthodontic setup. ${ }^{9}$

On the contrary, skeletal maturity "or bone age" can be determined by the maturation of one or more tissues including skeletal, dental, and sexual maturity. ${ }^{10}$

The visual inspection of bones, their first appearance, and related changes in shape and size are tools for assessing skeletal maturity. Many structures have been used as indicators like frontal sinus, elbow, foot, hand-wrist, and cervical vertebrae. ${ }^{11}$

Skeletal maturity indicators based on hand-wrist radiograph are reliable and simple; however, there has 
been increased interest in the usage of cervical vertebral maturation (CVM) as a replacement for the hand-wrist assessment that requires an additional radiographic film. $^{12-14}$

Despite a plethora of studies which have confirmed the validity of the cervical maturation CVM method for evaluating the maturation level, ${ }^{15}$ other clinical studies have demonstrated that the CVM method has weak reliability and repeatability. ${ }^{16-18}$

The precision of estimating CVM stages varies due to possible bias that may occur throughout qualitative description of cervical vertebral shape on two-dimensional (2D) cephalogram. ${ }^{16-18}$

Recent studies have scrutinized the possibility of using CBCT to assess the bone age, taking advantage of the appearance of cervical vertebrae in the field of view of CBCT image. ${ }^{19-21}$

Chen et $\mathrm{al}^{22}$ solved the limitations of $2 \mathrm{D}$ method of CVM by developing a quantitative analytical method from the sagittal view. Similarly, the study of Yang et al ${ }^{23}$ found an increased ability of bone age estimation by using quantitative shape analysis from axial view of cervical vertebrae compared with the chronological age.

Therefore, most of those studies focused on the general morphology of cervical vertebrae more than the additional information provided by CBCT as a 3D approach, like bone mineral density and volume measurement. ${ }^{19-21}$

It is widely acknowledged that the growth of body structures occurs in three-dimensions (3D) in width, then in the anteroposterior dimension, and finally in the vertical dimension respectively. ${ }^{24,25}$

Hence, and as the cervical vertebrae appear in CBCT field of view, the aim of this study has been to evaluate the correlation between quantitative assessment of cervical vertebral volumetric parameters and the skeletal maturity status in orthodontic patient.

This, in purpose, preludes for the development of a new method.

\section{MATERIALS AND METHODS}

The study population included 50 patients ( 29 girls and 21 boys aged between 8 and 16 years) selected randomly from the Department of Orthodontics and Dentofacial Orthopedics, at the Faculty of Dental Medicine, Damascus University.

All subjects included in this study had to meet the following criteria: (1) Syrians by nationality, (2) well nourished, free of any serious illness, and with normal growth and developmental conditions, (3) have no cleft lip or palate, and (4) have no previous trauma or injury in the head and neck region. A fifth criterion addresses the availability of CBCT radiograph including at least the entirely of the 4 th cervical vertebra.

Nonetheless, patients suffering from congenital or acquired malformations affecting cervical vertebrae or hand-wrist were excluded.

This study was approved by the ethics committee, the Council of Higher Education and Scientific Research at Damascus University (Ref. 2327/2016), and informed consent was obtained from all patients taking participation in this investigation.

All patients had a digital radiograph of the left-hand middle phalanx of the third finger, MP3, using X-MIND appliance (de Götzen company, Italy 2003 settings used: tube voltage $70 \mathrm{KV}$, tube current $8 \mathrm{~mA}$, scan time $25 \mathrm{~ms}$ ).

The skeletal maturity was assessed using Perinetti et $\mathrm{al}^{26}$ method which includes five stages referred to via (Fig. 1)

- MP3-F: Epiphysis is narrower than or as wide as metaphysis but with both tapered and rounded lateral borders.

- MP3-FG: Epiphysis is at least as wide as the metaphysis with sides increasing in thickness and showing a clear line of demarcation at right angle, either with or without lateral steps on the upper contour.

- MP3-G: Epiphysis is either as wide as or wider than the metaphysis with lateral sides showing initial capping toward the metaphysis.

- MP3-H: Epiphysis begins to fuse with the metaphysis although contour of the former is still clearly recognizable. The capping may still be detectable.

- MP3-I: Epiphysis is totally fused with the metaphysis. All CBCT radiographs were taken by one appliance (Scanora ${ }^{\circledR}$ 3D, Tusula, Sordrx company, Finland; settings used: tube voltage $85 \mathrm{KV}$, tube current $15 \mathrm{~mA}$, scan time $20 \mathrm{~s}$, voxel size $0.25 \mathrm{~mm}$, field of view cylindrical with height of $145 \mathrm{~mm}$ and diameter of $130 \mathrm{~mm}$ ).

The CBCT radiographs were obtained in upright position with maximum intercuspation. And patient's Frankfurt horizontal plane was set parallel to the floor.

The CBCT data were reconstructed using 3D imaging software (OnDemand3D, CyberMed, Finland) and then the radiographs were coded by four-digit number before assessment.

The investigator opened DICOM of CBCT image using software (Mimics Medical 19, company Materialise technologielaan, Belgium). The image thresholds were set to 226 to 3071 to mark the bony structures.

The body of the $2 \mathrm{nd}, 3 \mathrm{rd}$, and 4 th vertebra was cropped and other structures were deleted.

Each vertebra was isolated using split mask tool, then 3D format of each vertebra was obtained, and its 3D volume in $\mathrm{mm}^{3}$ was recorded using $3 \mathrm{D}$ object properties (Fig. 2). 

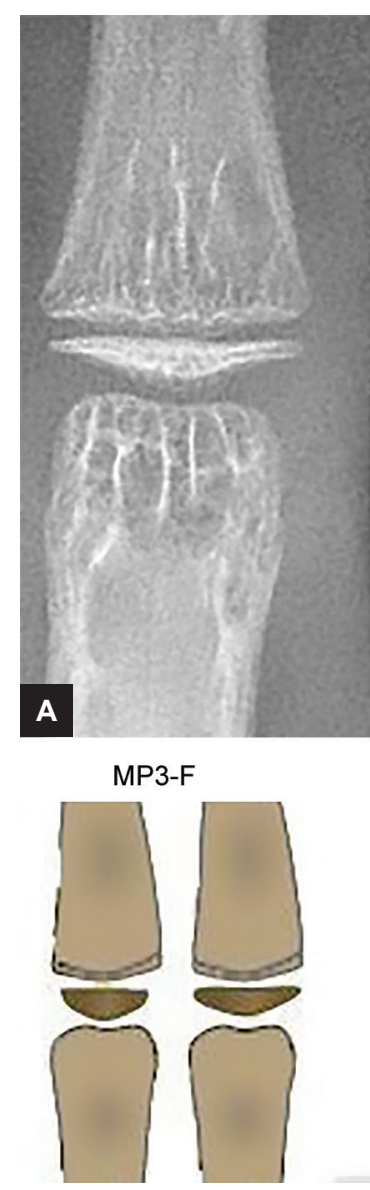

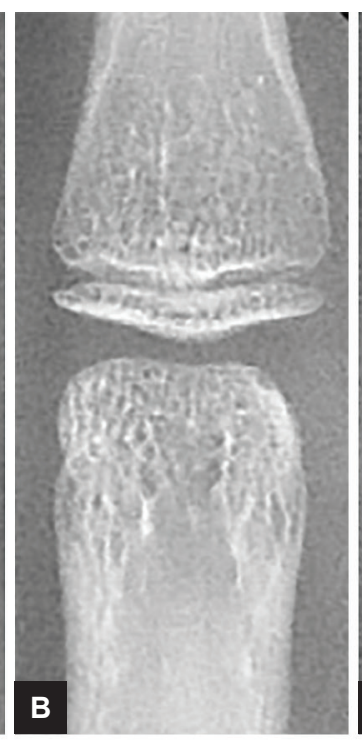

B

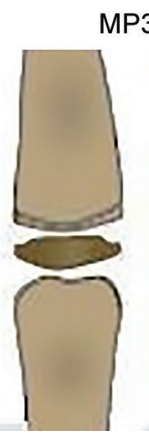

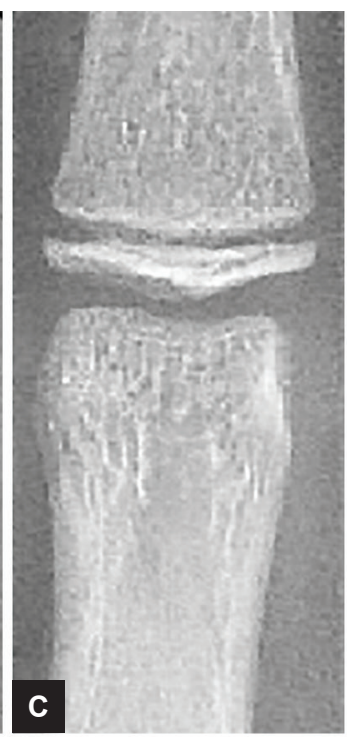

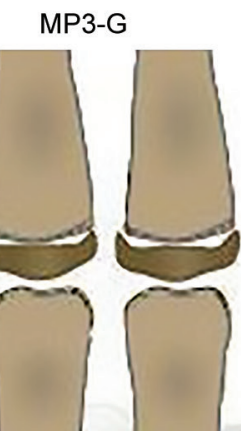

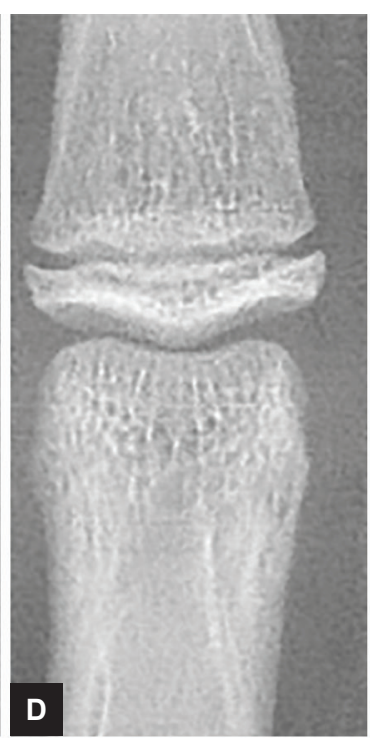

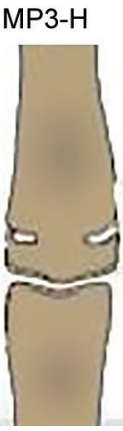

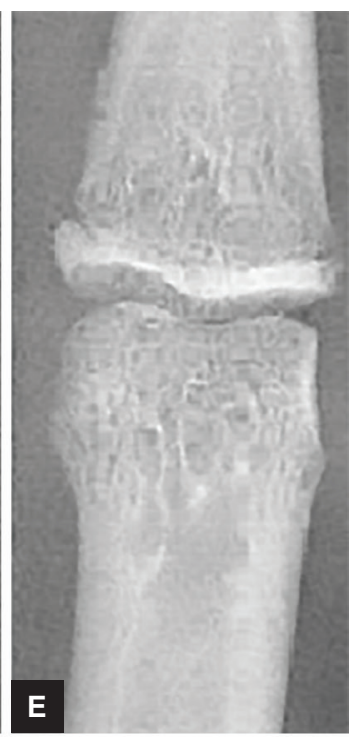

MP3-I

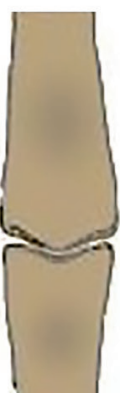

Figs 1A to E: Five stages of MP3: Perinetti et $\mathrm{al}^{26}$ method, "study radiographs"
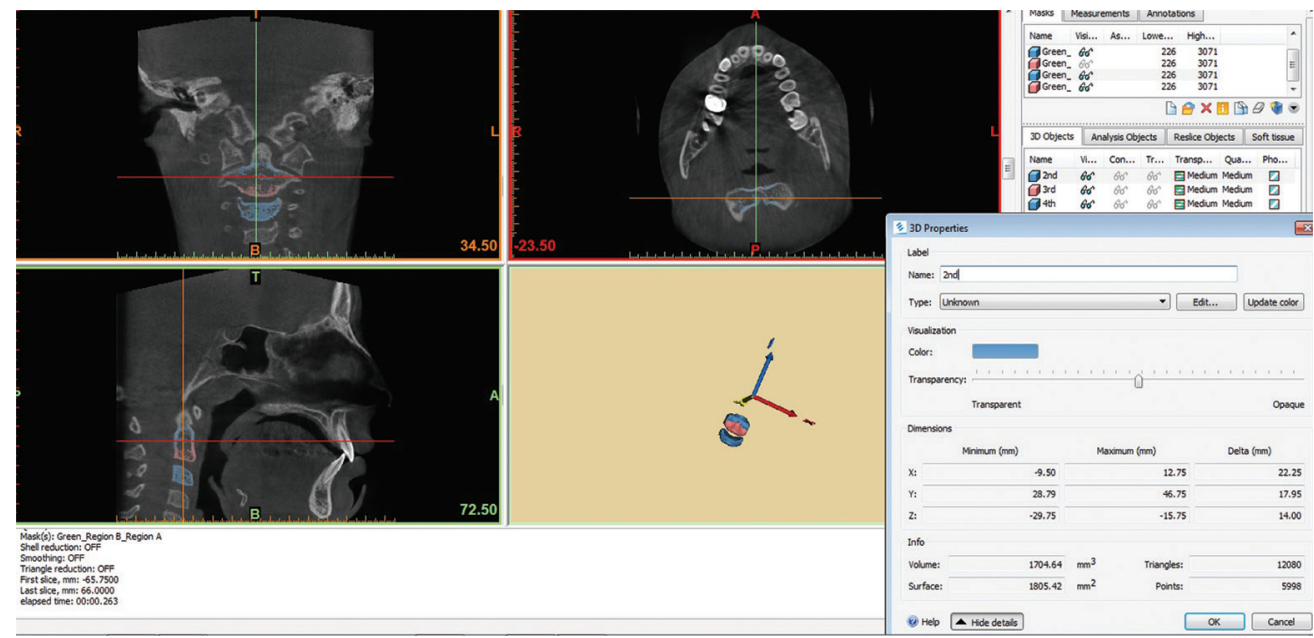

Fig. 2: Measuring 2nd vertebra body volume

The statistical study was conducted using statistical software (Statistical Package for the Social Sciences version 21.0 for Windows, Chicago, Illinois, USA) with a p-value $<0.05$.

The intraexaminer reliability of the quantitative measurements of volume was each checked by remeasuring 20 randomly selected CBCT data after 2 weeks; the intraclass correlation coefficients were very high (means of 0.994).
The intraobserver errors of the MP3 stages were assessed using Cohen's kappa index. The intraobserver and interobserver reliability for Cohen's kappa index each demonstrated substantial agreement (means of 0.815 ).

Analysis of variance and Bonferroni tests were utilized to evaluate the differences between the means of CVVPs among the MP3 stages.

The relation between skeletal maturity status depending on the MP3 method and the volumetric parameter of 
Cervical Vertebrae Volume Parameter and Skeletal Maturation Status

Table 1: Descriptive statistics of cervical vertebrae volume $\left(\mathrm{mm}^{3}\right)$

\begin{tabular}{|c|c|c|c|c|c|c|}
\hline & \multicolumn{2}{|c|}{ CVVP2 } & \multicolumn{2}{|c|}{ CVVP3 } & \multicolumn{2}{|c|}{ CVVP4 } \\
\hline & Mean & $S D$ & Mean & $S D$ & Mean & $S D$ \\
\hline MP3-F & 1302.739 & 379.1295 & 1381.705 & 214.1038 & 1771.805 & 380.5914 \\
\hline MP3-FG & 1302.3 & 448.3026 & 1398.935 & 448.3026 & 1791.255 & 462.4849 \\
\hline MP3-G & 1398.675 & 378.1069 & 1438.161 & 287.8663 & 1825.141 & 455.2163 \\
\hline MP3-H & 1990.426 & 641.8469 & 1917.542 & 441.5437 & 2555.141 & 785.2829 \\
\hline MP3-I & 2116.392 & 728.0676 & 2146.77 & 514.8801 & 3153.308 & 608.8262 \\
\hline
\end{tabular}

SD: Standard deviation

Table 2: ANOVA test for differences in CVVP between MP3 stages

\begin{tabular}{lllll}
\hline Vertebra & $\begin{array}{l}\text { Volume } \\
\text { mean }\end{array}$ & $\begin{array}{l}\text { Standard } \\
\text { deviation }\end{array}$ & $\begin{array}{l}\text { Test } \\
\text { value }\end{array}$ & $\begin{array}{l}\text { Level of } \\
\text { significance }\end{array}$ \\
\hline Second vertebra & 1622.106 & 649.002 & 4.990 & $0.002^{*}$ \\
Third vertebra & 1656.623 & 529.295 & 6.405 & $0.000^{*}$ \\
Fourth vertebra & 2219.330 & 792.477 & 11.038 & $0.000^{*}$ \\
\hline
\end{tabular}

${ }^{*} p<0.01$

each vertebra was evaluated using Spearman correlation coefficient analysis.

\section{RESULTS}

The sample population of 29 girls and 21 boys (total: $50,8-16$ years, and mean age: 11.5 years) was assigned to five skeletal maturation groups (MP3-F/MP3-FG/ MP3-G/MP3-H/MP3-I), each with 10 participants. The descriptive statistics of CVVP (obtained CBCT) are shown in Table 1.

The ANOVA test demonstrated differences between the means of vertical vertebrae volume among the MP3 stages (p-value <0.05) (Table 2).

Bonferroni test showed significant differences among the following MP3 stages and vertebrae (Table 3).

Second vertebra: MP3-I stage and both of MP3-F and MP3-FG stages.

Third vertebra: MP3-I stage and each of MP3-F/ MP3-FG/ and MP3-G stages.

Fourth vertebra: (a) MP3-I stage and each of MP3-F/ MP3-FG / and MP3-G stages. (b) MP3-F stage and MP3-H stage.

Spearman correlation coefficient analysis demonstrated an association between the volumetric parameters and the MP3 stages. The intensity of correlation ranged between moderate, for the whole sample, and strong, in the female groups for 3rd and 4th CVVP. However, it ranged between weak, for the whole sample, and moderate, in the female group for the 2nd CVVP (Table 4).

\section{DISCUSSION}

Several studies have used the MP3 method as a gold standard to determine the skeletal maturity. ${ }^{27-29}$

Depending on what has been previously provided, this study has used the MP3 maturation index as a
Table 3: Bonferroni test for differences in CVVP between MP3 stages

\begin{tabular}{|c|c|c|c|c|}
\hline \multirow{3}{*}{$\begin{array}{l}\text { Vertebra } \\
\text { Second } \\
\text { vertebra }\end{array}$} & \multicolumn{2}{|c|}{ Maturation stage } & \multirow{2}{*}{$\begin{array}{l}\text { Differences } \\
\text { mean }\end{array}$} & \multirow{2}{*}{$\begin{array}{l}\begin{array}{l}\text { Level of } \\
\text { significance }\end{array} \\
1.000\end{array}$} \\
\hline & MP3-F & MP3-FG & & \\
\hline & & MP3-G & -95.936 & 1.000 \\
\hline & & MP3-H & -687.687 & 0.091 \\
\hline & & MP3-I & -813.653 & $0.023^{*}$ \\
\hline & MP3-FG & MP3-G & -96.375 & 1.000 \\
\hline & & MP3-H & -688.126 & 0.090 \\
\hline & & MP3-I & -814.092 & $0.023^{*}$ \\
\hline & MP3-G & MP3-H & -591.751 & 0.234 \\
\hline & & MP3-I & -717.717 & 0.066 \\
\hline & MP3-H & MP3-I & -125.966 & 1.000 \\
\hline \multirow{10}{*}{$\begin{array}{l}\text { Third } \\
\text { vertebra }\end{array}$} & MP3-F & MP3-FG & -17.230 & 1.000 \\
\hline & & MP3-G & -56.456 & 1.000 \\
\hline & & MP3-H & -535.837 & 0.093 \\
\hline & & MP3-I & -765.065 & $0.003^{* *}$ \\
\hline & MP3-FG & MP3-G & -39.226 & 1.000 \\
\hline & & MP3-H & -518.607 & 0.116 \\
\hline & & MP3-I & -747.835 & $0.004^{*}$ \\
\hline & MP3-G & MP3-H & -479.381 & 0.191 \\
\hline & & MP3-I & -708.609 & 0.008 \\
\hline & MP3-H & MP3-I & -229.228 & 1.000 \\
\hline \multirow{10}{*}{$\begin{array}{l}\text { Fourth } \\
\text { vertebra }\end{array}$} & MP3-F & MP3-FG & -19.450 & 1.000 \\
\hline & & MP3-G & -53.336 & 1.000 \\
\hline & & MP3-H & -783.336 & $0.046^{*}$ \\
\hline & & MP3-I & -1381.503 & $0.000^{* *}$ \\
\hline & MP3-FG & MP3-G & -33.886 & 1.000 \\
\hline & & MP3-H & -763.886 & 0.056 \\
\hline & & MP3-I & -1362.053 & $0.000^{* *}$ \\
\hline & MP3-G & MP3-H & -730.000 & 0.079 \\
\hline & & MP3-I & -1328.167 & $0.000^{* *}$ \\
\hline & MP3-H & MP3-I & -598.167 & 0.276 \\
\hline
\end{tabular}

${ }^{*} p<0.05 ;{ }^{* *} p<0.01$

standard for comparison to reduce the amount of radiation exposed to patient who will take a CBCT radiograph.

Several methods of evaluating bone age have been introduced. ${ }^{30-33}$ The CVM method has proven useful. Mito et $\mathrm{al}^{34}$ and $\mathrm{Chen}$ et $\mathrm{al}^{35}$ invented a regression formula to obtain cervical vertebral bone age, using ratios of measurements in the $3 \mathrm{rd}$ and 4 th cervical vertebral bodies as independent variables. Byun et $\mathrm{al}^{36}$ added measurements of the $\mathrm{C} 2$ vertebral body and the odontoid process to these multiple regression models. However, these previous 


\begin{tabular}{|c|c|c|c|c|c|}
\hline Vertebra & Sex & Count & Test value & Level of significance & Test indication \\
\hline \multirow[t]{3}{*}{ Second vertebra } & All samples & 50 & 0.470 & $0.001^{*}$ & Weak positive correlation \\
\hline & Males & 21 & 0.375 & 0.094 & Weak positive correlation \\
\hline & Females & 29 & 0.555 & $0.002^{*}$ & Moderate positive correlation \\
\hline \multirow[t]{3}{*}{ Third vertebra } & All samples & 50 & 0.576 & $0.000^{* *}$ & Moderate positive correlation \\
\hline & Males & 21 & 0.432 & $0.050^{*}$ & Weak positive correlation \\
\hline & Females & 29 & 0.704 & $0.000^{* *}$ & Strong positive correlation \\
\hline \multirow[t]{3}{*}{ Fourth vertebra } & All samples & 50 & 0.644 & $0.000^{* *}$ & Moderate positive correlation \\
\hline & Males & 21 & 0.529 & $0.014^{*}$ & Moderate positive correlation \\
\hline & Females & 29 & 0.740 & $0.000^{* *}$ & Strong positive correlation \\
\hline
\end{tabular}

${ }^{*} p<0.05 ;{ }^{* *} p<0.01$

studies concentrated on 2D data despite 3D changes in cervical vertebrae dimensions.

The 2D CVM method also presents several problems including the inconsistent changes in skeletal development during the growth period, a high level of intra- and interobservation error during the tracing activities of lateral cephalometric radiography, and inaccurate measurements of bone mass. ${ }^{17}$

Henceforth, this study reiterates that the $3 \mathrm{D}$ growth of the human being evaluating the skeletal maturity using $3 \mathrm{D}$ approach is highly essential.

The aim of this study was to determine the correlation between volumetric parameters of cervical vertebrae and the skeletal maturity, using CBCT instead of 2D measurements.

The volumetric parameters varied between MP3 stages; the variant was greater in the parameters of the 4 th vertebra. Bonferroni test showed that the variations between MP3 stages in the 2nd and 3rd vertebra concentrated around two intervals: (a) MP3-I stage that represents the ending of changes and maturation and (b) the previous stages.

Nevertheless, in the 4 th vertebra, the variations have been found to be similar to the aforementioned along with variation between the stages (MP3-F/MP3-FG) before the peak of maturation and the stages (MP3-H/ MP3-I) after it.

Therefore, the differences in the 4th CVVP reflect the development in the maturation stages more than those of the 2nd and 3rd CVVP.

The increase in MP3 maturity stage was associated with increase in CVVP. When examining the correlation between each cervical vertebra's volume and the MP3 stages, the correlation for the 2nd vertebra was the lowest and the correlation for the 4 th vertebra was the highest.

One study ${ }^{37}$ in the literature examined cervical vertebrae volume as a skeletal maturity index and found similar results to that of the current study, that the correlation between 2nd CVVP and MP3 stages was not statistically significant in males, whereas it was weak in females.
Choi et $\mathrm{al}^{37}$ stated that in females, the change in the maturity status in accordance with the volume level was relatively consistent throughout the process: a rapid increase in maturation increases the volume level while the volume of the 2 nd cervical vertebra in men changes drastically during the pubertal growth peak.

For the 3rd CVVP, the correlation was significant in both male and female groups. This result is supported by

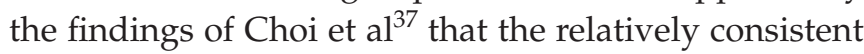
increase in maturation exists as the volume increases regarding the male and female groups.

Finally, the 4th CVVP was highly correlated to MP3 stages, especially in females where the correlation was significant and strong. Choi et $\mathrm{al}^{37}$ reported similar results.

A study of Crawford et $\mathrm{a}^{38}$ supports the results of this study. They suggested that remodeling occurs in C2 more than $\mathrm{C} 3$ producing more changes in volume of $\mathrm{C} 2$ compared with $\mathrm{C} 3$. On the contrary, the growth of $\mathrm{C} 3$ is more consistent due to the less resorption which occurs in this vertebra.

In accordance with the results of the current study, Altan et $\mathrm{al}^{39}$ also cited that the growth in $\mathrm{C} 2$ exhibited twice the amount of growth in C3; they demonstrated that the changes in growth of $\mathrm{C} 3$ are more consistent during growth period and, as result, reflecting the maturity status more accurately than that of $\mathrm{C} 2$.

The methods of Lamparski, ${ }^{40} \mathrm{O}^{\prime}$ Reilly and Yanniello, ${ }^{32}$ and the modification of Baccetti et $\mathrm{al}^{14}$ proved that the CVM index is a useful tool in orthopedic treatment. Conversely, the bias that may occur when determining patients' skeletal maturity is inevitable and hard to quantify. $^{6}$

A number of studies tried to overcome this drawback by developing a quantitative method to estimate a CVM index $22,23,34,36,41$ using many ratios of measurements derived from $\mathrm{C} 2$ to $\mathrm{C} 5$ vertebrae, which may be difficult to apply in clinical application.

Therefore, this study proposes a simple and accurate method to estimate the skeletal maturity status by measuring C4 volume. 
The CVM method is superior to the middle phalanx maturation method because it is performed on routine radiographs without the need for additional images.

Additional studies are needed to address the divergence regarding sexual dimorphism and ethnicity during the growth period.

\section{CONCLUSION}

With the limitations of the current study, it could be concluded that:

- Sufficient correlation exists between the five stages of $\mathrm{MP}^{26}$ and CVVP.

- The highest correlation was for the 4th CVVP.

- The correlation was higher in girls; however, the gender differences were not significant.

\section{CLINICAL SIGNIFICANCE}

Measurement of volumes of the 4th CVVP could be used as a simple quantitative analysis in clinical practice to evaluate the maturity in orthodontic patients.

\section{REFERENCES}

1. Silveira AM, Fishman LS, Subtelny JD, Kassebaum DK. Facial growth during adolescence in early, average and late maturers. Angle Orthod 1992 Fall;62(3):185-190.

2. Flores-Mir C, Burgess CA, Champney M, Jensen RJ, Pitcher MR, Major PW. Correlation of skeletal maturation stages determined by cervical vertebrae and hand-wrist evaluations. Angle Orthod 2006 Jan;76(1):1-5.

3. Moore RN, Moyer BA, DuBois LM. Skeletal maturation and craniofacial growth. Am J Orthod Dentofacial Orthop 1990 Jul;98(1):33-40.

4. Lewis AB, Garn SM. The relationship between tooth formation and other maturation factors. Angle Orthod 1960 Apr;30(2):70-77.

5. Hunter CJ. The correlation of facial growth with body height and skeletal maturation at adolescence. Angle Orthod 1966 Jan;36(1):44-54.

6. Björk A, Helm S. Prediction of the age of maximum pubertal growth in body height. Angle Orthod 1967 Apr;37(2):134-143.

7. Tofani MI. Mandibular growth at puberty. Am J Orthod 1972 Aug;62(2):176-195.

8. Hagg U, Taranger J. Menarche and voice change as indicators of the pubertal growth spurt. Acta Odontol Scand 1980;38(3):179-186.

9. Dhiman S, Maheshwari S, Verma SK. Assessment of maturity in orthodontics: a review. J Adv Clin Res Insights 2015 Mar-Apr;2(2):100-103.

10. Demirjian A, Buschang PH, Tanguay R, Patterson DK. Interrelationship among measures of somatic, skeletal, dental and sexual maturity. Am J Orthod 1985 Nov;88(5):433-438.

11. Leite HR, O'Reilly MT, Close JM. Skeletal age assessment with the first, second and third fingers of the hand. Am J Orthod Dentofacial Orthop 1987 Dec;92(6):492-498.

12. San Román P, Palma JC, Oteo MD, Nevado E. Skeletal maturation determined by cervical vertebrae development. Eur J Orthod 2002 Jun;24(3):303-311.
13. Franchi L, Baccetti T, McNamara JA Jr. Mandibular growth as related to cervical vertebral maturation and body height. Am J Orthod Dentofacial Orthop 2000 Sep;118(3):335-340.

14. Baccetti T, Franchi L, McNamara J. An improved version of the cervical vertebral maturation (CVM) method for the assessment of mandibular growth. Angle Orthod 2002 Aug;72(4):316-323.

15. Gandini P, Mancini M, Andreani F. A comparison of hand-wrist bone and cervical vertebral analysis in measuring skeletal maturation. Angle Orthod 2006 Nov;76(6): 984-989.

16. Nestman TS, Marshall SD, Qian F, Holton N, Franciscus RG, Southard TE. Cervical vertebrae maturation method morphologic criteria: poor reproducibility. Am J Orthod Dentofacial Orthop 2011 Aug;140(2):182-188.

17. Gabriel DB, Southard KA, Qian F, Marshall SD, Franciscus RG, Southard TE. Cervical vertebrae maturation method: poor reproducibility. Am J Orthod Dentofacial Orthop 2009 Oct;136(4):478.e1-478.e7.

18. Santiago RC, de Miranda Costa LF, Vitral RW, Fraga MR, Bolognese AM, Maia LC. Cervical vertebral maturation as a biologic indicator of skeletal maturity. Angle Orthod 2012 Nov;82(6):1123-1131.

19. Shi H, Scarfe WC, Farman AG. Three-dimensional reconstruction of individual cervical vertebrae from cone-beam computed tomography images. Am J Orthod Dentofacial Orthop 2007 Mar;131(3):426-432.

20. Shim JJ, Heo G, Lagravère MO. Assessment of skeletal maturation based on cervical vertebrae in CBCT. Int Orthod 2012 Dec;10(4):351-362.

21. Joshi V, Yamaguchi T, Matsuda Y, Kaneko N, Maki K, Okano T. Skeletal maturity assessment with the use of conebeam computerized tomography. Oral Surg Oral Med Oral Pathol Oral Radiol 2012 Jun;113(6):841-849.

22. Chen L, Liu J, Xu T, Long X, Lin J. Quantitative skeletal evaluation based on cervical vertebral maturation: a longitudinal study of adolescents with normal occlusion. Int J Oral Maxillofac Surg 2010 Jul;39(7):653-659.

23. Yang YM, Lee J, Kim YI, Cho BH, Park SB. Axial cervical vertebrae-based multivariate regression model for the estimation of skeletal-maturation status. Orthod Craniofac Res 2014 Aug;17(3):187-196.

24. Proffit, WR.; Fields, HW.; Sarver, DM. Contemporary orthodontics. St. Louis (MO): Mosby; 2012.

25. Singh IJ, Savara BS. Norms of size and annual increments of seven anatomical measures of maxillae in girls from three to sixteen years of age. Angle Orthod 1966 Oct;36(4):312-324.

26. Perinetti G, Sbardella V, Contardo L. Diagnostic reliability of the third finger middle phalanx maturation (MPM) method in the identification of the mandibular growth peak. Eur J Orthod 2016 Sep;39(2):194-201.

27. Patil AA, Revankar AV. Reliability of the frontal sinus index as a maturity indicator. Indian J Dent Res 2013 Jul-Aug;24(4):523.

28. Hegde G, Hegde N, Kumar A, Keshavaraj. A new system for assessment of growth using mandibular canine calcification stages and its correlation with modified MP3 stages. J Pharm Bioallied Sci 2014 Jul;6(Suppl 1):S58-S63.

29. Surendran S, Thomas E. Tooth mineralization stages as a diagnostic tool for assessment of skeletal maturity. Am J Orthod Dentofacial Orthop 2014 Jan;145(1):7-14.

30. Hagg U, Taranger J. Maturation indicators and the pubertal growth spurt. Am J Orthod 1982 Oct;82(4):299-309. 
31. Uysal T, Sari Z, Ramoglu S, Basciftci F. Relationships between dental and skeletal maturity in Turkish subjects. Angle Orthod 2004 Oct;74(5):657-664.

32. O'Reilly MT, Yanniello GJ. Mandibular growth changes and maturation of cervical vertebrae-a longitudinal cephalometric study. Angle Orthod 1988 Apr;58(2):179-184.

33. Greulich, WW.; Pyle, SI. Radiographic atlas of skeletal development of the hand and wrist. 2nd ed. Stanford (CA): Stanford University Press; 1959.

34. Mito T, Sato K, Mitani H. Cervical vertebral bone age in girls. Am J Orthod Dentofacial Orthop 2002 Oct;122(4):380-385.

35. Chen F, Terada K, Hanada K. A new method of predicting mandibular length increment on the basis of cervical vertebrae. Angle Orthod 2004 Oct;74(5):630-634.

36. Byun, BR.; Kim, YI.; Yamaguchi, T.; Maki, K.; Son, WS. Quantitative assessment of cervical vertebral maturation using cone beam computed tomography in Korean girls. Comput Math Methods Med 2015 Mar;2015:1-9.
37. Choi YK, Kim J, Yamaguchi T, Maki K, Ko C, Kim Y. Cervical vertebral body's volume as a new parameter for predicting the skeletal maturation stages. Biomed Res 2016 May;2016:1-7.

38. Crawford B, Kim DG, Moon ES, Johnson E, Fields HW, Palomo JM, Johnston WM. Cervical vertebral bone mineral density changes in adolescents during orthodontic treatment. Am J Orthod Dentofacial Orthop 2014 Aug;146(2):183-189.

39. Altan M, Nebioğlu Dalci Ö, İseri H. Growth of the cervical vertebrae in girls from 8 to 17 years. A longitudinal study. Eur J Orthod. 2012 Jun;34(3):327-34.

40. Lamparski, DJ. Skeletal age assessment utilizing cervical vertebrae [Ph.D. thesis]. Pittsburgh (PA): University of Pittsburgh; 1972.

41. Byun BR, Kim YI, Yamaguchi T, Maki K, Ko CC, Hwang DS, Park SB, Son WS. Quantitative skeletal maturation estimation using cone-beam computed tomography-generated cervical vertebral images: a pilot study in 5- to 18-year-old Japanese children. Clin Oral Investig 2015 Nov;19(8):2133-2140. 